\title{
Spatial variation in onset dates and trends in phenology across Europe
}

\author{
Christoph Schleip ${ }^{1}$, Tim H. Sparks ${ }^{2,3}$, Nicole Estrella ${ }^{1}$, Annette Menzel ${ }^{1, *}$ \\ ${ }^{1}$ Fachgebiet für Ökoklimatologie, Technische Universität München, Am Hochanger 13, 85354 Freising-Weihenstephan, Germany \\ ${ }^{2}$ Natural Environment Research Council, Centre for Ecology \& Hydrology, Huntingdon, Cambridgeshire PE28 2LS, UK \\ ${ }^{3}$ Present address: 68 Girton Road, Girton, Cambridge CB3 0LN, UK
}

\begin{abstract}
This study presents an approach based on the Bayesian paradigm to identify and compare observed changes in the timing of phenological events in plants. Previous studies have been based mostly on linear trend analyses. Our comprehensive phenological dataset consists of long-term observational records (>30 yr) within the 1951-1999 period across central Europe, from which we selected 2600 quality-checked records of 90 phenophases (mostly in spring and summer). We estimated the model probabilities and rates of change (trends) of 3 competing models: (1) constant (mean onset date), (2) linear (constant trend over time) and (3) change point (time-varying change). The change point model involves the selection of 2 linear segments which match at a particular time. The matching point is estimated by an examination of all possible breaks weighted by their respective change point probability. Generally we found more pronounced changes in maritime Western and Central Europe. The functional behaviour of all 2600 time series was best represented by the change point model $(62 \%)$, followed by the linear model $(24 \%)$; the constant model was the least preferred alternative. Therefore, non-linear phenological changes were by far the most commonly observed feature, especially in Western Europe. Regression analyses of change point model probabilities against geographic coordinates and altitude resulted in some significant negative regression coefficients with longitude; in contrast, the constant model probabilities increased with longitude. Even when differences between locations across Europe existed, an overall trend towards earlier flowering was determined at most locations. Multiple regressions confirmed that mean advancing trends in the 1990s were stronger in the northwestern part of the study area.
\end{abstract}

KEY WORDS: Bayesian analysis · Change point model $\cdot$ Phenology $\cdot$ Central Europe $\cdot$ Climate change $\cdot$ Impact

Resale or republication not permitted without written consent of the publisher

\section{INTRODUCTION}

Phenology is a field of research which studies the annual rhythm of biological phenomena mainly related to climate (Schnelle 1955). Centuries ago, especially for agricultural purposes, phenological knowledge improved the understanding of the variation in life cycle events. Today, several European countries still have active phenological monitoring networks and continuous long-term data series (Menzel 2003). Their data have recently been collected by the COST 725 action (www.cost725.org). Although an old and traditional science, phenology is still relevant to present day activities and policies and has attracted increasing attention in recent years. Since climate change due to global warming may invoke massive problems for mankind and nature, the interest has focused on the possible and already observed impacts of climatic changes in nature (Rosenzweig et al. 2007). Many studies show that the timing of phenophases such as the date of first flowering, budbreak, unfolding of first leaf, first bird migration or egg laying is correlated with climate variables (Sparks \& Carey 1995, Ahas 1999, Crick \& Sparks 1999, Schwartz 1999, Sparks 1999, Sparks et al. 2000, Menzel et al. 2001, 2006, Sparks \& Menzel 2002, Menzel 2003, Schwartz et 
al. 2006). Evidence from long-term phenological monitoring studies in Europe is now accumulating (e.g. Rosenzweig et al. 2008), and results show that the past climate variation and recent climatic and atmospheric trends are already having impacts on species physiology, distribution and phenology (e.g. Hughes 2000). Earlier spring development is occurring in different parts of Europe: Ahas (1999) reported that springtime had advanced $8 \mathrm{~d}$ on average over the last $80 \mathrm{yr}$ and even faster over the last 40 yr. Menzel \& Fabian (1999) and Menzel (2000) analysed phenological data from the International Phenological Gardens for the period 1969-1998 and detected that the average beginning of the growing season across Europe advanced by $8 \mathrm{~d}$. These results and many other long-term phenological monitoring studies emphasize that phenology is a fundamental topic within global change science (see recent reviews by Walther et al. 2002, Parmesan \& Yohe 2003, Root et al. 2003, Rosenzweig et al. 2007).

In the present study, we focus on long-term phenological time series of $\geq 30 \mathrm{yr}$ within the period 1951-1999 on well-distributed and recorded plants in Central Europe. Only a few phenological studies cover more than $30 \mathrm{yr}$, and some have already detected a near European-wide warming in early spring over the last $30 \mathrm{yr}$ with a corresponding progressively earlier onset of spring and summer phenophases (Menzel \& Fabian 1999, Defila \& Clot 2001, Ahas et al. 2002, Chmielewski \& Rötzer 2002, Sparks \& Menzel 2002, Estrella et al. 2007). However, the results of these studies were mostly based on linear trend analyses. With the Bayesian concept, which is applied in the present study, we are able to compare model probabilities to describe the records and their resulting aggregated trends. A challenge of the present and similar studies (Schleip et al. 2006, 2008, Menzel et al. 2008) is to emphasise the importance of phenological processes in nature. A single day is the smallest temporal resolution of most phenological observations in vegetation, forest growth, crop and pollen forecast models (Schaber 2002). When causes and patterns of plant phenological reaction to climate change are analysed, the intrinsic uncertainty and variability of phenological data must be considered. Keeping this variability in mind, the present study aims to identify and quantitatively compare regional differences in trends between several phenophases and species across Europe. Specifically, we compare the probabilities of the change point model to other classical models (linear and constant) indicating the best fit to the observational records. The resulting mean trends, averaged for the 1990s, of 8 phenophases spanning the relevant seasons are analysed and compared to variations in the onset of phenophases at the end of the 20th century.

\section{METHODS}

\subsection{Phenological data}

We used phenological data from the database of the 5 FP-EU Project POSITIVE - Phenological Observation and Satellite Data (NDVI): Trends in the Vegetation Cycle in Europe (contract no. EVK2-CT-199900012). The data comprised phenological records on common species including herbs, agricultural crops, fruit and forest trees. The observation stations included $>2600$ time series of a defined seasonal event. In total, 119 different phenological events were recorded in this comprehensive dataset. Not all stations included the same species and phenophases. Most of the data consisted of spring and summer phenophases such as leaf unfolding or flowering, but also included autumn phenophases such as leaf colouring and leaf fall. The phenological observations provided a good geographical coverage for Central, Eastern and part of Western Europe (Austria, Switzerland, Germany, Slovenia, Poland, Estonia and the former Soviet Union [hereafter 'Russia']) within the period 1951-1999 (Table 1). The longitudes and latitudes of the observational stations ranged from 5 to $65^{\circ} \mathrm{E}$ and 45 to $65^{\circ} \mathrm{N}$, respectively, and the altitudes from 0 to $1400 \mathrm{~m}$ above sea level. A quality check following the method of Scheifinger et al. (2002) was conducted to exclude outliers and single observations which had been possibly incorrectly recorded.

The minimum number of observational years required at a single station was set to 30 . Ninety of the 119 phenophases met these selection criteria. Thus our corrected European phenological dataset included 2600 quality-checked phenological time series of $\geq 30$ yr comprising 90 phenological phases and covering a geographical range of $6^{\circ} 17^{\prime}$ to $63^{\circ} 7^{\prime} \mathrm{E}$ and $45^{\circ} 98^{\prime}$ to $61^{\circ} 81^{\prime} \mathrm{N}$. Substantial differences in observed species and the recorded years existed among the surveyed countries. Consequently, the spatial density of all available series was different between phenophases and countries: there were fewer data available

Table 1. Country codes and number of stations. The former Soviet Union includes a few stations in Belarus, Ukraine, Lithuania and Latvia

\begin{tabular}{|lcc|}
\hline Country & Country code & No. stations \\
\hline Estonia & EST & 11 \\
Switzerland & CH & 22 \\
Slovenia & SLO & 8 \\
Austria & A & 48 \\
Germany & G & 36 \\
Former Soviet Union & RUS & 41 \\
Poland & PL & 13 \\
\hline
\end{tabular}


for Eastern Europe, compared to Western Europe, because only a few long-term ( $\geq 30$ yr) observational records were available in countries such as Russia, Poland and Estonia.

\subsection{Models}

The Bayesian analysis of the time series follows the methodology introduced by Dose \& Menzel (2004), to which we refer for computational details; for a more user-friendly explanation we recommend Schleip et al. (2006). Within this section we limit our explanations of the Bayesian analysis on the fitting of competing models. The results of the time series description are given in annual numbers of change point probability or trend; in the latter part of the present study a subset of these results for the 1990s is further analysed.

Three different models were used to describe the time series. The constant model represents the hypothesis of no change with a functional behaviour constant in time and an associated zero rate of change. The linear model assumes a linear change of the observed phenomenon with an associated constant rate of change. The change point model allows for a timevarying rate of change and thus is an indicator for nonlinear changes. Its development starts from triangular functions, hence 2 linear segments, which match at particular change point choices. The change point model function has one variable at the beginning of the time series in Year $\mathrm{x}_{1}$ with the assumed functional value $f_{1}$, and another variable at the endpoint of the time series in Year $\mathbf{x}_{\mathrm{N}}$ with the assumed functional value $f_{N}$. Although the endpoints of the time series remain fixed in the subsequent calculations, the intermediate Year $\mathrm{x}_{\mathrm{E}}$ with associated functional value $\mathrm{f}_{\mathrm{E}}$ can assume all Years $\mathrm{x}_{2} \leq \mathrm{x}_{\mathrm{E}} \leq \mathrm{x}_{\mathrm{N}-1}$ (Dose \& Menzel 2004). The support functional values, as well as the change point of the 2 linear sections making up the triangular function, are variables of the calculation (Dose \& Menzel 2004). If $\mathrm{N}$ is the number of entries on the time scale, there are $\mathrm{N}-2$ possibilities (excluding the endpoints) for the change point position. Within the Bayesian analysis, all possible triangular functions for the present data were overlapped and weighted by their respective change point probability which leads to the change point function.

The probabilities of the 3 models for each time series were also calculated from Bayesian model theory. If none of the 3 models exhibits a dominant probability, then we eliminate the variable 'model' from the calculation by a marginalization step, superimposing the 3 answers for functional behaviour and trend weighted by the respective model probabilities. The latter averaging process does not modify the shape of the trend derived from the change point model, but adds an offset due to the constant contribution from the linear model and a modification of the amplitude by the amount of model probability obtained for the change point model. This latter model-averaged information for functional behaviour and trend has been used in the present study. As the trend information is given annually, resulting average changes in the 1990s, at the end of the time series, could be calculated.

First, the model probabilities were used to investigate which model best described the observations. Starting from a general analysis over all the phenophases, the entire corrected dataset was used to determine if the model probabilities changed under certain conditions. All 2600 time series of the European dataset were examined and grouped by country, ordered from west to east. In this very broad and general screening test, the single probabilities were first examined separately for each phenophase and site and were then grouped and summarised.

Altitudinal gradients were studied for alpine countries such as Austria, Germany and Switzerland. For the most complete and best distributed 8 phenophases, multiple regression analyses were used to investigate the dependence of model probabilities on altitude, longitude and latitude. Interpolated maps (triangle-based interpolation method with Delaunay criterion, de Floriani \& Puppo 1992) were produced to show the spatial distribution of the mean onset dates and resulting trends for the 1990s.

For 2 selected phenophases, maps illustrate the model probabilities and the phenological trends at European stations, allowing for a visual spatial assessment of the temporal patterns in phenological changes.

\section{RESULTS}

\subsection{Model probabilities over all phenophases by country and altitude}

Viewed over all countries and records, the change point model had the highest probability, with maximum results near $100 \%$ and an overall mean of $61.9 \%$ (Fig. 1). With a closer look at the single probabilities for each country, it can be seen that western European countries had higher change point probabilities than eastern European countries. Change point probabilities for Switzerland and Germany ranked at the top with medians of 68 and $65 \%$, respectively. For Estonia, Poland and Russia, the $95 \%$ confidence intervals of the medians included the $50 \%$ change point probability limit (dashed vertical line in Fig. 1), while only for Russia did median probability fall below $50 \%$. 


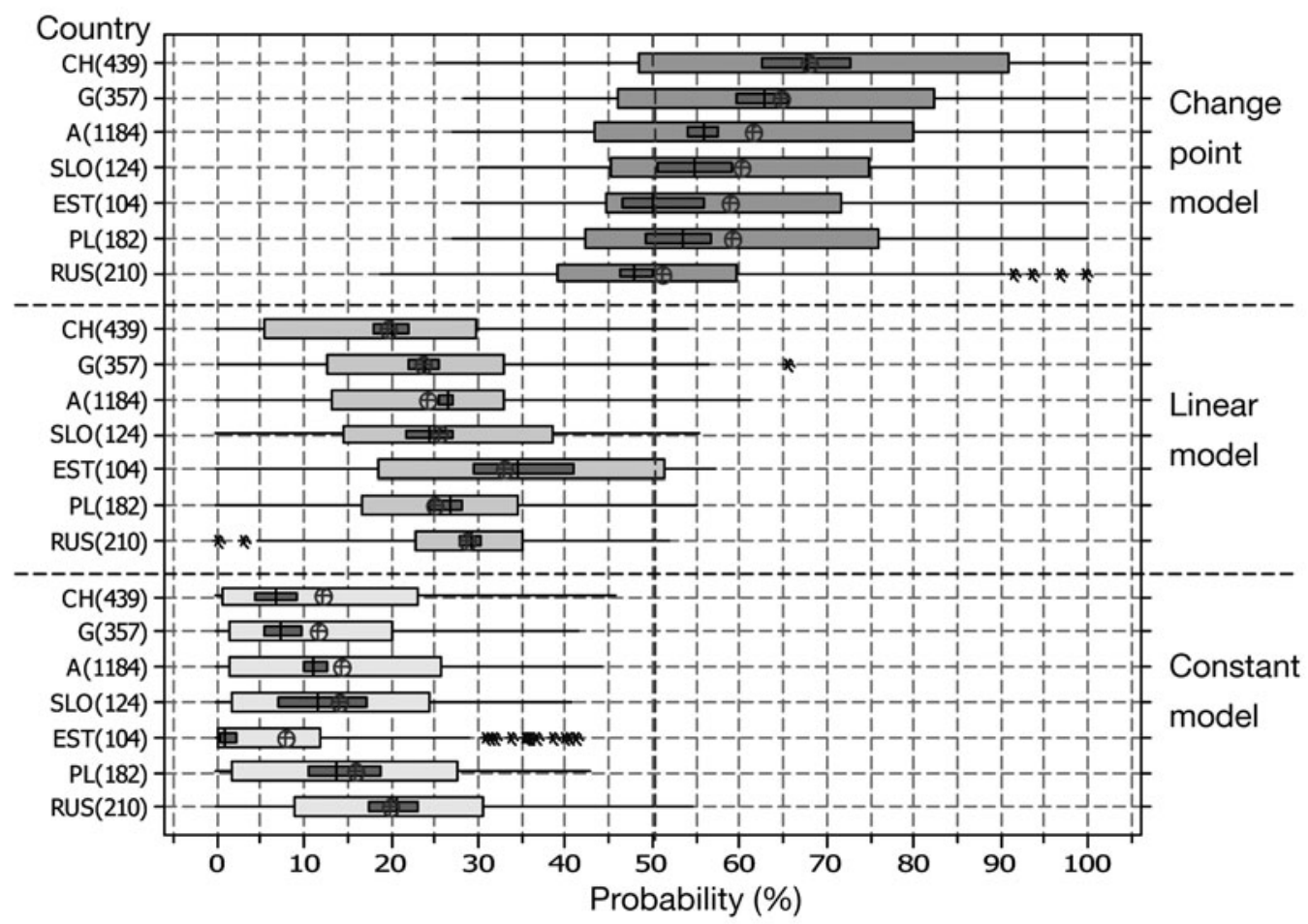

Fig. 1. Boxplots of model probabilities for all 2600 time series, separated by country. Number of time series are in parentheses next to the country codes (see Table 1). Inner grey box is the $95 \%$ CI for the median; 25th and 75th percentiles are at either end of the box; the range is indicated by the horizontal line. Outliers ( $>2 \mathrm{SD}$ ) are marked as asterisks; the median is denoted by a verti-

cal line; the mean is denoted by the circle with a cross; vertical dashed line marks the $50 \%$ change point probability limit

The linear model ranked second. On average, nearly a quarter and up to a maximum of $61.1 \%$ of all time series best fit this functional description. In Austria, Estonia, Poland and Russia the linear model frequently had probabilities $>25 \%$. The median in Estonia for the linear model probability model was $33 \%$, a substantial fraction compared to the other model probabilities. In only about $14.4 \%$ of all time series did the constant model prove to be the best functional solution. There were rare cases where its probability reached a maximum of $55 \%$.

In general, there was a strong preference for the change point model, indicating a more abrupt change in phenology in recent decades in Europe. As the countries in Fig. 1 are grouped from west to east, it is obvious that mean probabilities of the change point model were higher in Western Europe. In the same way, the probabilities for the linear and constant models, indicating gradual or no change, respectively, increased with eastern longitude.

Change point model probabilities did not rise constantly with altitude. With a median of $55.5 \%$ at altitudes of about $1000 \mathrm{~m}$ a.s.l., the change point probability was relatively low compared to the median value at $900 \mathrm{~m}(65.7 \%)$ and at $1100 \mathrm{~m} \mathrm{(77.7 \% )} \mathrm{(Fig.} \mathrm{2).}$ Relatively high change point model probabilities of around $70 \%$ (median) were also reached at the highest altitudes, $>1200$ and $>1300$ m a.s.l.

\subsection{Dependence of geographical position on model probability, mean onset and model-averaged trends}

For 8 selected phases (see Table 2), the influence of the geographic position of the observation site was tested by multiple regression analyses. The model probabilities of the 3 models, the mean onset of the 1990s and the resulting model-averaged annual trend for the 1990s were used as dependent variables. The regression equation was calculated with Latitude, Longitude, Altitude and Country as independent variables. The variable Country turned out to be insignificant; therefore, the regression equation was recalculated with only the geographic coordinates and altitude (Table 2). The following description will concentrate on the regression equations without country as a factor.

Table 2 shows the results of the regression analysis of model probabilities and geographic coordinates including altitude. The influence of geographic position varies strongly among models and phenophases. For Sorbus aucuparia beginning of flowering (BF), 


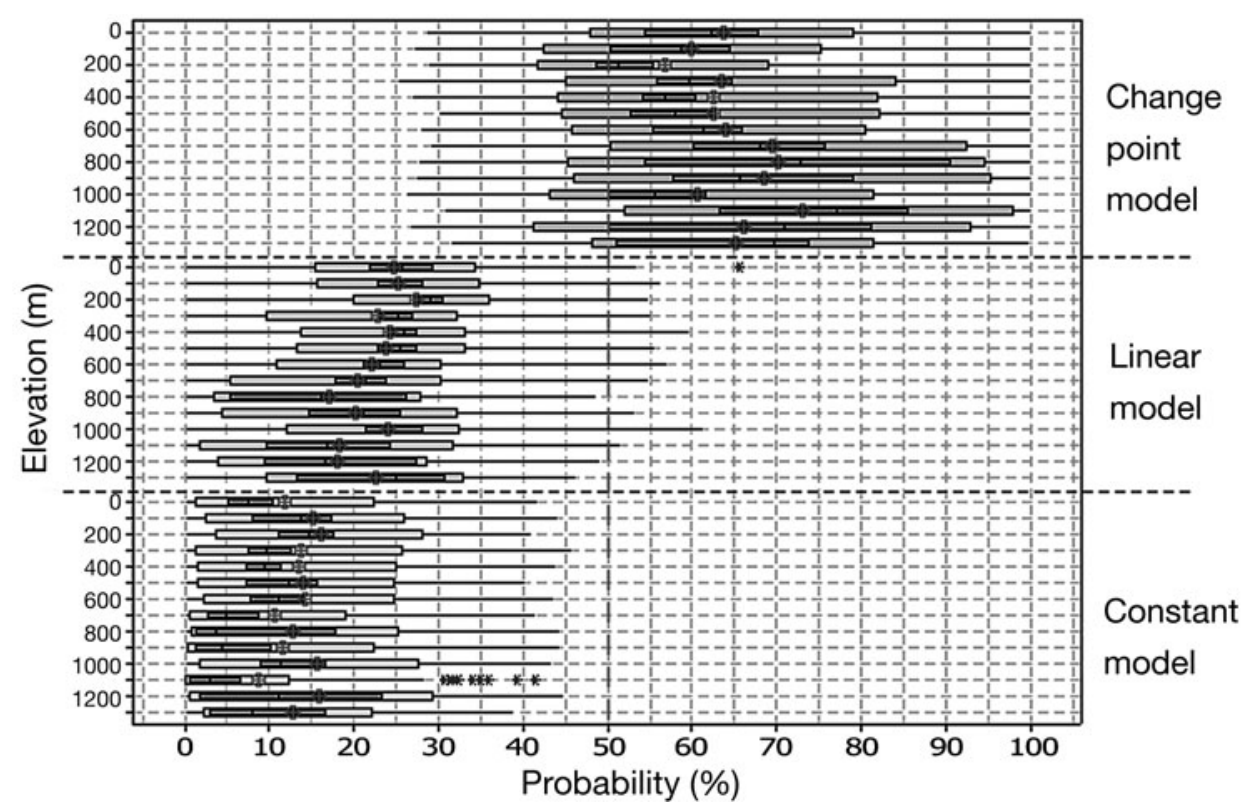

Fig. 2. Model probabilities of all phenophases at different altitudes in the Alpine region (Austria, Switzerland and Germany). For symbol description see Fig. 1 . Number of time series varies with elevation: $<100 \mathrm{~m}=90 ; 100-200 \mathrm{~m}=105 ; 201-300 \mathrm{~m}=215$; $301-400 \mathrm{~m}=279 ; 401-500 \mathrm{~m}=364 ; 501-600 \mathrm{~m}=165 ; 601-700 \mathrm{~m}=216 ; 701-800 \mathrm{~m}=146 ; 801-900 \mathrm{~m}=31 ; 901-1000 \mathrm{~m}=120 ;$ $1001-1100 \mathrm{~m}=92 ; 1101-1200 \mathrm{~m}=95 ; 1201-1300 \mathrm{~m}=35 ;$ and $>1301 \mathrm{~m}=27$

$42 \%$ of the linear model probability can be explained, for Syringa vulgaris BF $25 \%$. For the other 6 phenophases, the linear model probability is hardly (i.e. $\mathrm{R}^{2} \leq 0.2$ ) dependent on the geographic position of the site. Only 3 regression coefficients of latitude and 1 of longitude were significant and positive at the $5 \%$ level; for altitude, 2 coefficients were significant, but one was positive and the other negative.

The change point probability model explained 39 and $23 \%$ of the variation in Sorbus aucuparia BF and Corylus avellana $\mathrm{BF}$, respectively. The significant regression coefficients were positive for latitude and negative for longitude and altitude. Four phenophases showed strong geographical dependence for the model probabilities of the constant model; in addition, this regression analysis led to the most significant regression coefficients, positive for longitude and negative for latitude and altitude. However, it must be reiterated that the constant model was the least preferred model (see Fig. 1).

As expected, the mean onset dates in the 1990s were strongly influenced by geographic position and elevation (Table 2). All regression coefficients of the flowering and leaf unfolding phenophases were significant $\left(\mathrm{R}^{2}=0.59-0.81, \mathrm{p}<0.05\right)$ and positive. Only for the phenophase autumn leaf colouring (AC) of Betula pendula were the coefficients negative and significant (for latitude and longitude, but not for altitude). The course of the mean onset of the spring phases had a pro- nounced latitudinal and a weak longitudinal component leading to a $\mathrm{S}-\mathrm{N}$ onset pattern. Only Corylus avellana BF revealed a slightly larger SW-NW spread (see Fig. 4). The altitudinal gradient was between 2 and $5 \mathrm{~d}$ per $100 \mathrm{~m}$. The onset of Betula pendula AC moved from NE towards SW.

Finally, we analysed the geographic influence on the model-averaged trends for the 1990s (Table 2). The altitudinal regression coefficients were negligible. For 5 phenophases with $\mathrm{R}^{2} \leq 0.2$, the corresponding regression coefficients were all significant for longitude and, except for one, latitude. The longitudinal gradients were positive, the latitudinal negative. Therefore, stronger negative trends were situated in the NW and weaker negative or even positive trends can be expected in the SE.

\subsection{Spatial distribution of model probabilities for 2 selected phenophases}

The model probabilities for Syringa vulgaris BF in Eastern Europe, especially in Estonia, showed a strong preference for the linear model (Fig. 3b). On the other hand, Betula pendula AC showed a higher preference for the change point model. On both maps, the preference for the change point model is lower in eastern European countries and even acquires a high probability for the constant model at some stations (Fig. 3, blue dots). 
Table 2. Results of the multiple regression analysis, with dependent variables model probability, mean onset of the 1990s and model-averaged trend of the 1990s. BF: beginning of flowering; LU: leaf unfolding; AC: autumn colouring. Significant regression coefficients $(p<0.05)$ are in bold

\begin{tabular}{|c|c|c|c|c|c|c|}
\hline \multirow[t]{2}{*}{ Dependent variable } & \multirow[t]{2}{*}{ Phenophase } & \multirow[t]{2}{*}{$\mathrm{R}^{2}$} & \multicolumn{4}{|c|}{ _ Regression coefficient } \\
\hline & & & Intercept & Longitude & Latitude & Elevation \\
\hline \multicolumn{7}{|l|}{ Model probability } \\
\hline \multirow[t]{8}{*}{ Change point } & Corylus avellana BF & 0.23 & -123.23 & -0.310 & 3.319 & 0.044 \\
\hline & Tussilago farfara BF & 0.02 & 103.81 & 0.192 & -1.032 & -0.005 \\
\hline & Betula pendula LU & 0.02 & -14.20 & -0.241 & 1.53 & 0.019 \\
\hline & Taraxacum officinale BF & 0.03 & 33.12 & -0.107 & 0.44 & 0.014 \\
\hline & Malus domestica BF & 0.18 & -1.40 & -0.812 & 1.412 & 0.012 \\
\hline & Syringa vulgaris BF & 0.06 & 37.55 & -1.014 & 0.752 & 0.011 \\
\hline & Sorbus aucuparia BF & 0.39 & 152.73 & -0.489 & -1.473 & -0.015 \\
\hline & Betula pendula AC & 0.11 & -35.95 & -0.627 & 2.069 & 0.002 \\
\hline \multirow[t]{8}{*}{ Constant } & Corylus avellana BF & 0.16 & 143.72 & 0.481 & -2.511 & -0.026 \\
\hline & Tussilago farfara BF & 0.02 & -21.64 & -0.154 & 0.815 & 0.003 \\
\hline & Betula pendula LU & 0.01 & 43.56 & 0.126 & -0.647 & -0.006 \\
\hline & Taraxacum officinale BF & 0.01 & 16.35 & 0.064 & -0.045 & -0.005 \\
\hline & Malus domestica BF & 0.35 & 137.87 & 0.654 & -2.547 & -0.013 \\
\hline & Syringa vulgaris BF & 0.23 & 94.64 & 0.605 & -1.73 & -0.008 \\
\hline & Sorbus aucuparia BF & 0.32 & 87.04 & 0.647 & -1.639 & -0.004 \\
\hline & Betula pendula AC & 0.2 & 87.21 & 0.583 & -1.626 & -0.001 \\
\hline \multirow[t]{8}{*}{ Linear } & Corylus avellana BF & 0.09 & 79.52 & -0.171 & -0.809 & -0.018 \\
\hline & Tussilago farfara BF & 0 & 17.84 & -0.039 & 0.217 & 0.002 \\
\hline & Betula pendula LU & 0.02 & 70.64 & 0.116 & -0.883 & -0.013 \\
\hline & Taraxacum officinale BF & 0.02 & 50.55 & 0.042 & -0.395 & -0.009 \\
\hline & Malus domestica BF & 0.19 & -36.49 & 0.158 & 1.135 & 0.001 \\
\hline & Syringa vulgaris BF & 0.25 & -32.19 & 0.408 & 0.978 & -0.002 \\
\hline & Sorbus aucuparia BF & 0.42 & -139.75 & -0.158 & 3.111 & 0.019 \\
\hline & Betula pendula AC & 0.01 & 48.74 & 0.043 & -0.443 & -0.001 \\
\hline \multirow[t]{8}{*}{ Mean onset } & Corylus avellana BF & 0.62 & 101.71 & 1.876 & 2.294 & 0.051 \\
\hline & Tussilago farfara BF & 0.59 & -77.46 & 0.451 & 2.743 & 0.022 \\
\hline & Betula pendula LU & 0.81 & -44.18 & 0.141 & 2.737 & 0.037 \\
\hline & Taraxacum officinale BF & 0.75 & -57.51 & 0.199 & 3.01 & 0.034 \\
\hline & Malus domestica BF & 0.79 & -44.96 & 0.207 & 3.068 & 0.031 \\
\hline & Syringa vulgaris BF & 0.8 & -28.15 & 0.123 & 2.876 & 0.034 \\
\hline & Sorbus aucuparia BF & 0.81 & -44.18 & 0.141 & 2.737 & 0.037 \\
\hline & Betula pendula AC & 0.7 & 409.81 & -0.507 & -2.388 & -0.01 \\
\hline \multirow[t]{8}{*}{ Model-averaged trend } & Corylus avellana BF & 0.05 & 2.05 & 0.023 & -0.058 & $-1.59 \times 10^{-4}$ \\
\hline & Tussilago farfara BF & 0.03 & -0.25 & 0.008 & -0.002 & $-1.28 \times 10^{-4}$ \\
\hline & Betula pendula LU & 0.22 & 1.52 & 0.016 & -0.041 & $-1.25 \times 10^{-4}$ \\
\hline & Taraxacum officinale BF & 0.21 & 0.8 & 0.013 & -0.024 & $-3.48 \times 10^{-4}$ \\
\hline & Malus domestica BF & 0.28 & 0.61 & 0.016 & -0.023 & $-3.08 \times 10^{-4}$ \\
\hline & Syringa vulgaris BF & 0.25 & 0.53 & 0.014 & -0.022 & $-2.54 \times 10^{-4}$ \\
\hline & Sorbus aucuparia BF & 0.22 & 1.52 & 0.016 & -0.041 & $-1.25 \times 10^{-4}$ \\
\hline & Betula pendula AC & 0.06 & 0.45 & -0.003 & -0.003 & $-5.08 \times 10^{-4}$ \\
\hline
\end{tabular}

\subsection{Maps of mean onset dates and mean trends in the 1990s}

Maps of mean onset dates and mean trends in the 1990s are given in Figs. 4 \& 5 for 8 phenophases: Corylus avellana, Tussilago farfara, Taraxacum officinale, Syringa vulgaris, Malus domestica and Sorbus aucuparia $\mathrm{BF}$; Betula pendula leaf unfolding (LU); and $B$. pendula $\mathrm{AC}$, spanning seasons from early spring to autumn. In the 1990s, each spring phenophase had an earlier onset in Western Europe than in the east. In southwest Germany in particular, spring phenophases were characterised by a relatively early onset (Fig. 4). In the Baltic Basin, the latest onset of each spring phenophase was recorded. For species such as Tussilago farfara, Taraxacum officinale and Malus domestica, other areas of earlier flowering were those influenced by the Black Sea and surrounding the Carpathian Mountains (Fig. 4b,d,f). In Central Poland, some phenophases such as C. avellana, B. pendula and Syringa vulgaris BF had a more delayed onset (Fig. 4a,c,e). Tussilago farfara was an exception, with an earlier onset in Central Poland (Fig. 4b). Areas of more delayed onsets for nearly all spring phenophases were common in the Alpine countries. In autumn, an earlier colouring of the leaves of $B$. pendula in northeastern Europe and a later colouring in Western Europe were found (Fig. 4h). 

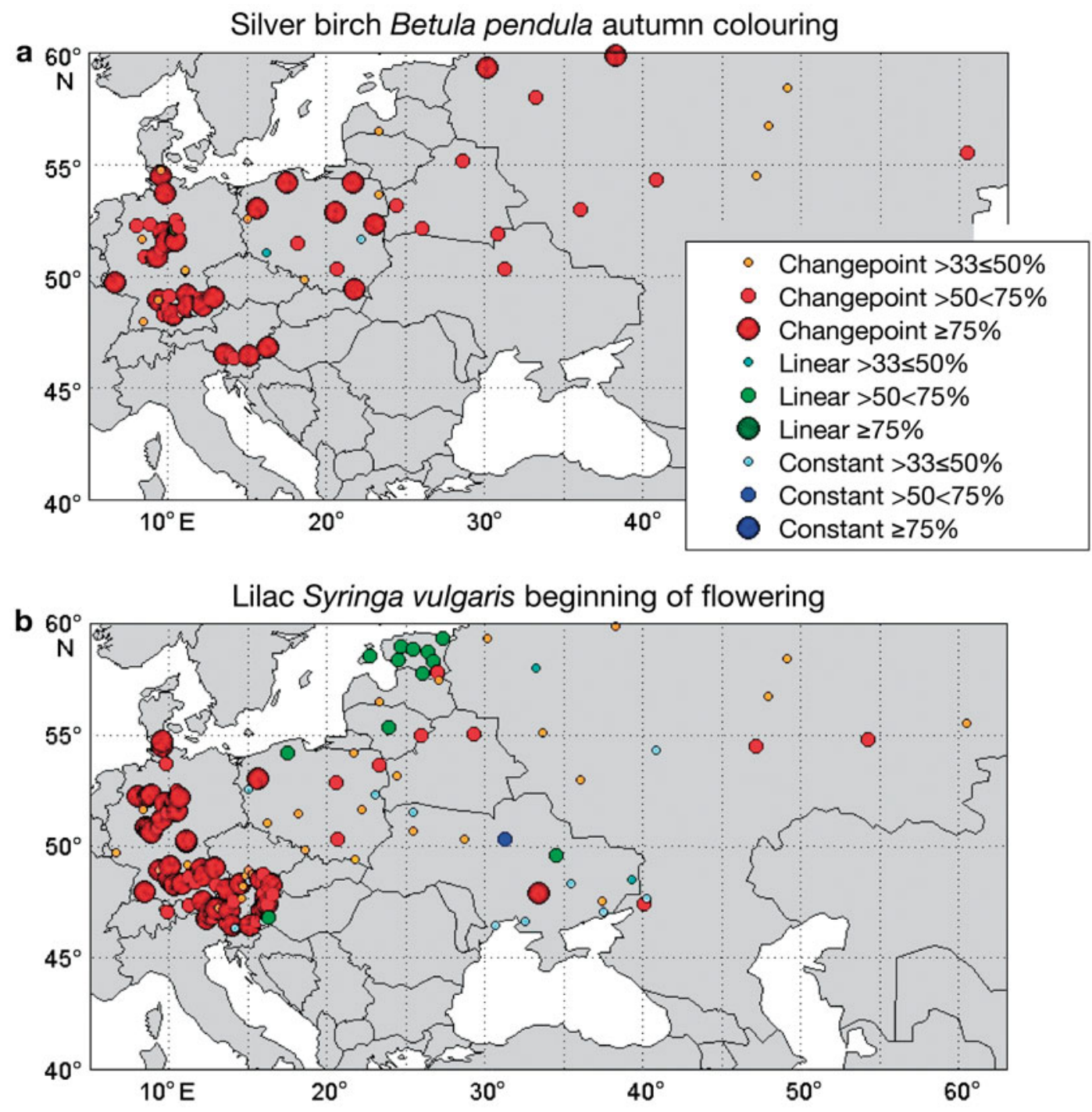

Fig. 3. Model probabilities of Betula pendula leaf autumn colouring and Syringa vulgaris beginning of flowering in Europe

These spatial patterns of mean onset dates were very similar to the distribution patterns of the trends. Western Europe has generally higher negative slopes than Eastern Europe. Spring phenophases, with the exception of Corylus avelana BF, nearly all showed negative trends of approximately $-0.5 \mathrm{~d} \mathrm{yr}^{-1}$ in the $1990 \mathrm{~s}$ for large areas of Germany (Fig. 5). The distribution of trends for C. avellana BF is striking (Fig. 5a). The higher slopes of negative trends were not confined to western parts of Europe, but advancing trends of $>1 \mathrm{~d} \mathrm{yr}^{-1}$ were also seen in Estonia, where maximum negative trends of more than $-1.5 \mathrm{~d} \mathrm{yr}^{-1}$ were reached.

The Alpine region revealed very variable trend patterns. For Corylus avellana, the Alps seemed to have a more delayed effect on the trends. However, other phenophases, such as Betula pendula LU and Taraxacum officinale $\mathrm{BF}$, had a negative trend of more than
-1 d yr $\mathrm{yr}^{-1}$, e.g. in parts of Austria. In southern Germany, Austria and Slovenia, trends were very often negative, with confidence intervals always below zero (Fig. 5c,d).

At one station in the Baltic Sea region, Betula pendula AC showed strong advancing trends of more than $-1.5 \mathrm{~d} \mathrm{yr}^{-1}$ (Fig. 5h). In general, a tendency towards a more delayed autumn colouring of leaves was observed in Western Europe than in the east.

\section{DISCUSSION}

There are many studies indicating climate change impacts on the phenology of plants; these frequently include long-term phenological monitoring studies in Europe (see Rosenzweig et al. 2007). The present study adds new aspects concerning the temporal patterns of 

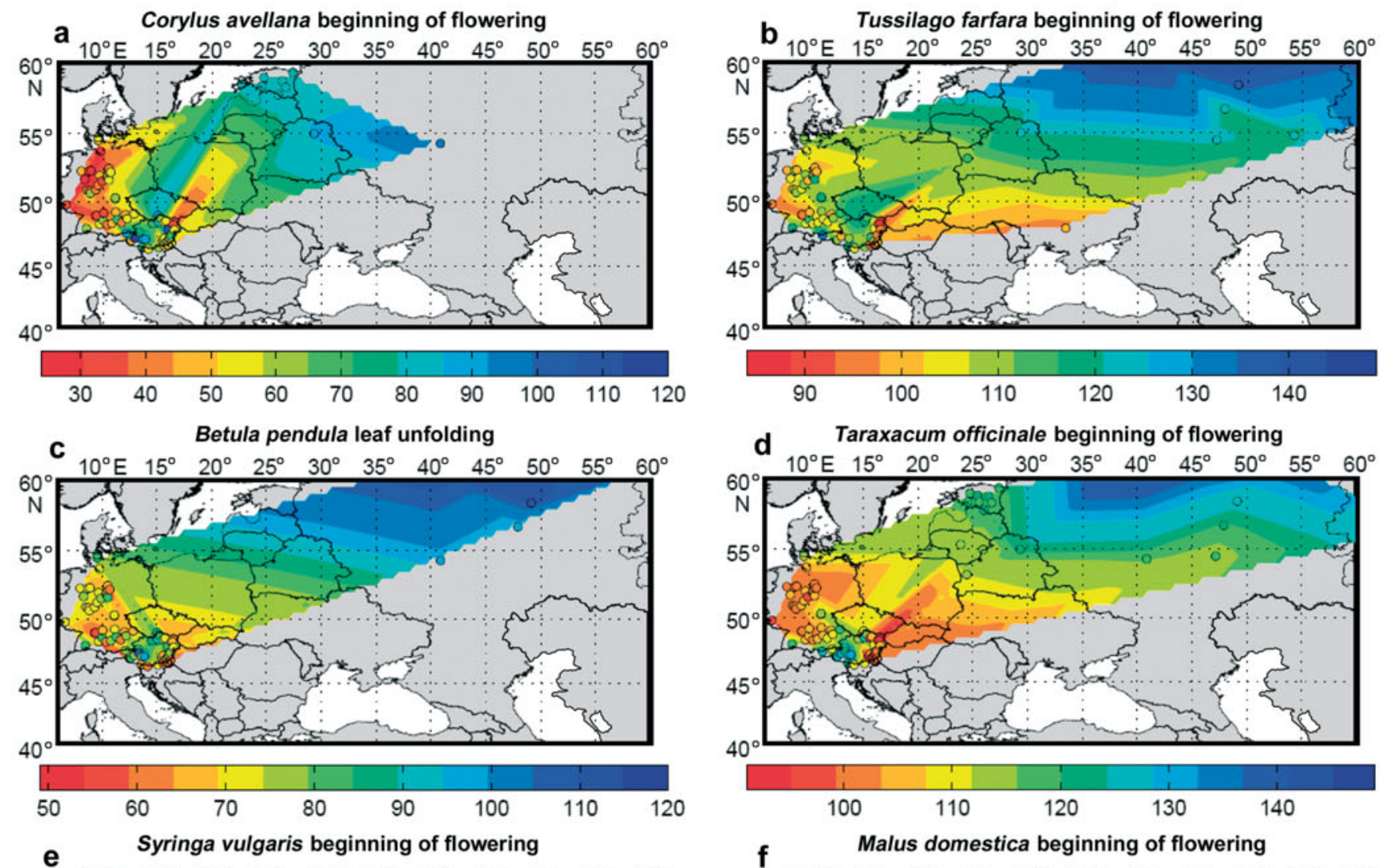

d Taraxacum officinale beginning of flowering
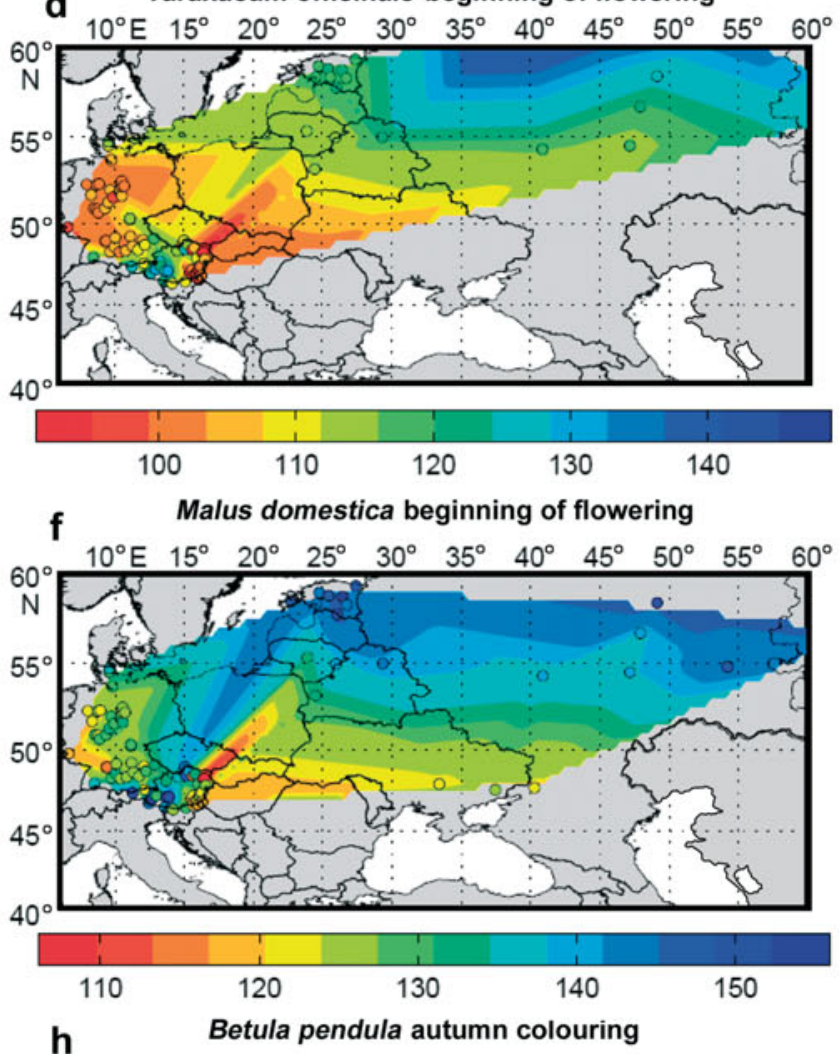

g Sorbus aucuparia beginning of flowering
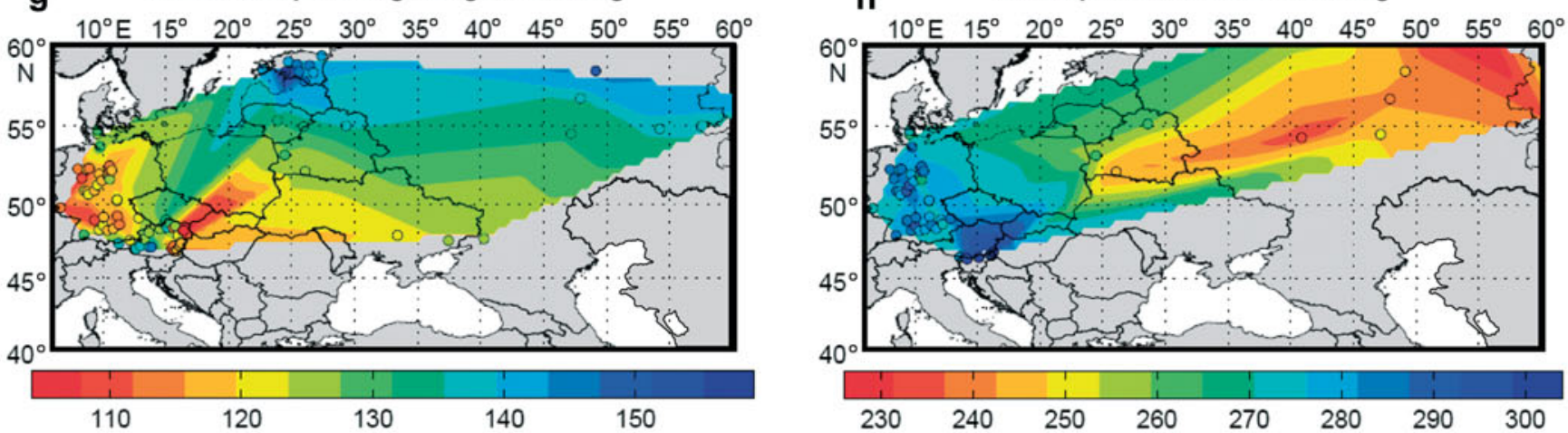

Fig. 4. Mean onset dates (since 1 January) in the 1990s for (a) Corylus avellana beginning of flowering (BF); (b) Tussilago farfara $\mathrm{BF}_{\text {; }}$ (c) Betula pendula leaf unfolding; (d) Taraxacum officinale BF; (e) Syringa vulgaris BF; (f) Malus domestica BF; (g) Sorbus aucuparia BF; and (h) Betula pendula autumn colouring. Each circle represents a station. Note that the scale bar refers to different onset days of the year (D.O.Y.) in each panel 

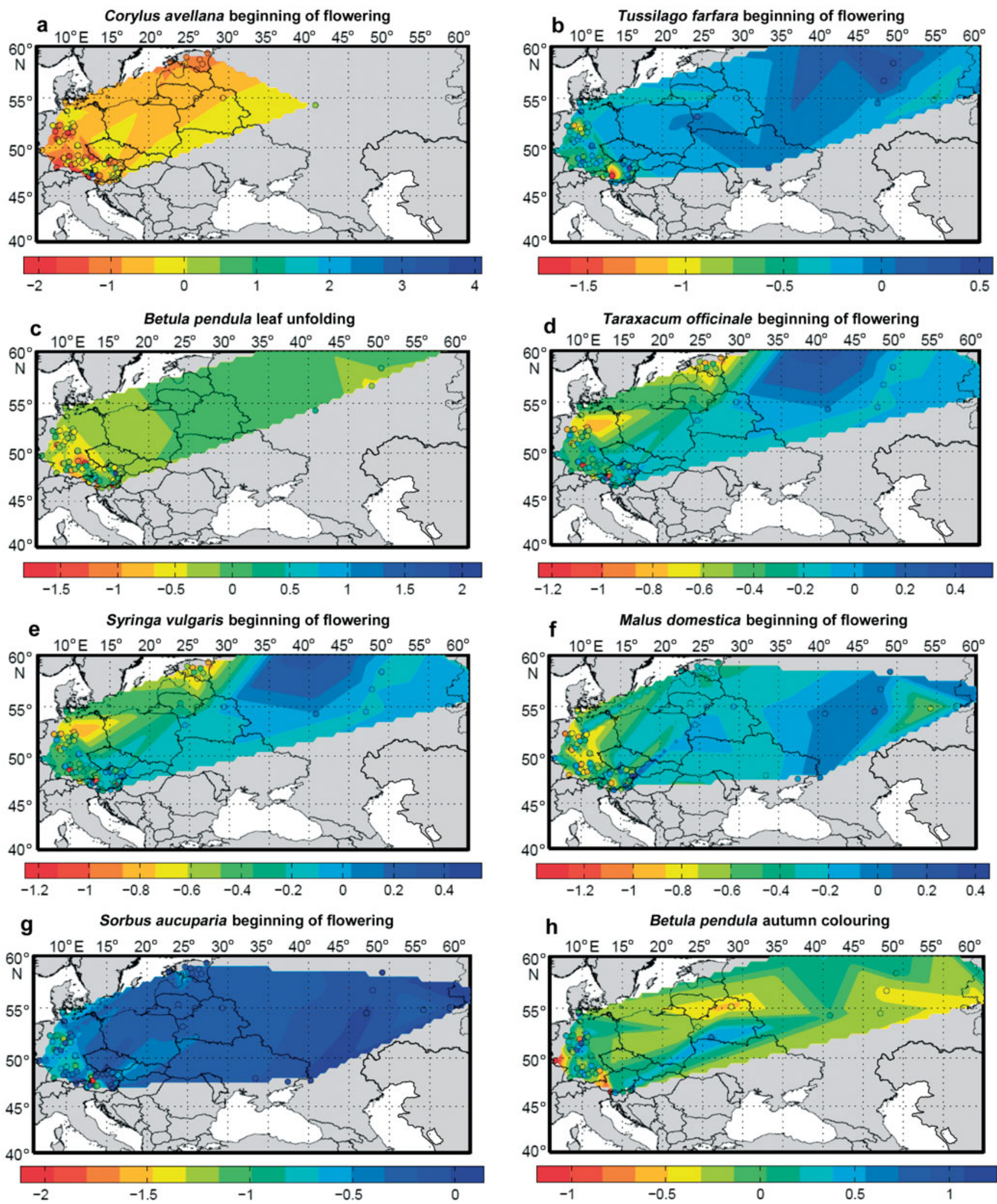

Fig. 5. Model-averaged trends of the 1990s decade for 8 selected key phenophases: (a) Corylus avellana beginning of flowering (BF); (b) Tussilago farfara BF; (c) Betula pendula leaf unfolding; (d) Taraxacum officinale BF; (e) Syringa vulgaris BF; (f) Malus domestica BF; (g) Sorbus aucuparia BF; and (h) Betula pendula autumn colouring. Each circle represents a station. Trends are reported in ${\mathrm{d} \mathrm{yr}^{-1}}^{-1}$ 
these changes, which were assessed by a Bayesian model comparison using a comprehensive common database of the EU-Project POSITIVE (identical to COST 725 database, plus some countries of the former Soviet Union). In accordance with other long-term phenological studies ( $\geq 30 \mathrm{yr}$ ), the present study also indicates an earlier occurrence of spring phenophases as a likely consequence of climate warming rather than normal climatic variability. However, the dominance of the change point model clearly underlines that these changes did not occur gradually, but more or less abruptly. In this sense, the present study confirms results showing a marked change towards an earlier onset in the mid-1980s in Central Europe (Chmielewski \& Rötzer 2002, Scheifinger et al. 2002, Dose \& Menzel 2004, Studer et al. 2005). The advantage of the present study is that its findings are solidly based on 2600 records of $\geq 30$ yr in 7 European countries.

This European-wide spread of observational data also allows an analysis of the spatial pattern of model probabilities and associated trends in Europe. In Eastern Europe, the dominance of the change point model is less prevalent compared to the linear and constant models, but is still the best fitted method to describe the functional behaviour. The linear model suggests rather continuous changes, perhaps due to a more steadily changing climate. The constant model could even hint to a fixed climate status quo or resilience against global impacts. However, according to the change point model most plants in Western Europe followed temporally uniform patterns in their phenological changes.

Besides climate warming, site-specific factors and genetic background may have a modifying impact on phenology. The onset of phenophases is also influenced by local landscape, maritime climate, land cover type, proximity of large bodies of water, elevation, local climate type, relief and vegetation pattern as well as other factors. In the present study, inherent phenological variability causes similar uncertainties as in conventional studies with other statistical methods.

Due to the broad spectrum of analysed species and phenophases, we can conclude from our analysis that species' phenophases often react in specific ways. Differences can be found between species and/or phenophases; some adapt quickly, and others do not. The early spring phenophases such as Corylus avellana, Tussilago farfara and Taraxacum officinale BF and Betula pendula LU seem to have reacted very quickly to a warming climate. Change point probabilities of early spring phenophases and corresponding trends are very diverse. Phenophases with quick changes are very likely associated with higher percentages of the change point model than phenophases which react more slowly or occur later in the year. The Bayesian temperature sensitivity analysis (Schleip et al. 2009) underlined the results of the present study. Schleip et al. (2009) indicated that plants showed different sensitivities to temperature changes according to the time of year of their onset. They found that we can distinguish between phenophases which show a prompt temperature response pattern and those phenophases with a delayed response pattern. They concluded that especially abrupt temperature changes during sensitive stages of species, mostly during spring, cause a change in the plant phenological date.

The interpolated maps of the long-term time series (Figs. 4 \& 5) of the mean onset dates and mean trends of 8 key phenophases in the 1990s may be biased. The density of observation sites in eastern European countries is too low and produces interpolations over large areas with barely interpretable values. We confirmed the S-N movement of the mean onset of the 1990s as detected visually for most of the spring phenophases with a multiple linear regression (Table 2b). In contrast, Menzel et al. (2005) reported a stronger W-E component for the spread of spring phenophases across Europe in warmer years. This difference might be due to a lack of western stations in the Atlantic and northern stations in Scandinavia in our analysis. Only mean onset of Corylus avellana contained a clear W-E gradient. The phenophase Betula pendula AC revealed expected negative gradients for all 3 geographical coordinates (latitude, longitude, altitude). The $\mathrm{R}^{2}$ of 0.7 was high for an autumn phase; this indicates that the continental gradient of the station distribution leads to a pronounced spread of this autumn phase from NNE to SSW.

The positive longitudinal and negative latitudinal gradient for the model-averaged trends are interesting (Table 2c). The latitudinal gradient is greater, leading to a stronger $\mathrm{N}-\mathrm{S}$ and a small $\mathrm{W}-\mathrm{E}$ component, meaning that northwestern stations have stronger negative model-averaged trends in the 1990s.

Comparing Fig. 3 with the results of the regression in Table 2a, we can prove that the regression equation for the change point probabilities for Betula pendula AC shows significant negative longitudinal and positive latitudinal regression coefficients. The interaction of these 2 gradients leads to lower values of the change point probability in the southeast. In contrast, the constant model probabilities follow a SE to NW gradient; however, few stations prefer the constant model in general. The map for Syringa vulgaris BF displays the high preference of the change-point model in Central Europe, the preference of the linear model in the Baltic states and the lower model probabilities in the East. The regression equations for the 3 model probabilities partly mirror this picture. The regression analysis of change point model probabilities explains $<10 \%$ of the 
variation in this phenophase, but this value increases to $25 \%$ for the linear model probabilities, and here the probabilities increase from NE to SW. The probabilities for the constant model display a SE to NW divide; this cannot be visually extracted from the map, again because too few stations prefer the constant model. The regression equations confirm that there are differences in the spatial distribution of model probabilities as well as in model-averaged trends of the 1990s. The spatial pattern for the model-averaged trends is uniform for 7 out of 8 analysed phenophases (except for the autumn phase): there is a strong decrease from NW to $\mathrm{SE}$, indicating that the shift to earlier BF is more pronounced in western stations and a delay of onset can be observed for eastern stations. Station elevation does not influence the model-averaged trend. Ziello et al. (2009, this Special) found some hints of altitudinal influence on trends, but the influence was weakly significant and their study area was concentrated in the Alpine region.

Results demonstrate that the assumed climate-driven changes reported in dates of spring phenophases occurred heterogeneously. There exist certain regions where phenological events have shifted towards an earlier date, e.g. in areas of western Germany or in the influence zone of the Black Sea and surrounding the Carpathian Mountains. However, an opposite shift towards a later phenological date was also observed in large areas such as central Poland and areas of the Baltic Basin. High mountains such as the Alps represent climate barriers and cause very high variability at small scales.

Our results concerning the European and regional trends of spring phenophases largely agree with those of Menzel (2000) concerning the seasonality of trends, and with those of Menzel \& Estrella (2001) and Ahas et al. (2002) concerning increased trends in Western Europe and the Baltic Sea region. In Ahas et al. (2002), the linear trends of Betula pendula LU and Syringa vulgaris $\mathrm{BF}$ are similar to the mean results of our analysis for the 1990s; however, the longitudinal change in trends differs due to the methods applied (e.g. here a delayed onset in Poland which was not seen in Ahas et al. 2002). Our results reveal more insight into the spatial patterns of phenology on a European-wide scale with a longitudinal variation in change point probability and general regional differentiation in resulting trends.

\section{LITERATURE CITED}

Ahas R (1999) Long-term phyto-, ornitho- and ichthyophenological time-series analyses in Estonia. Int J Biometeorol 42:119-123

Ahas R, Aasa A, Menzel A, Fedotova VG, Scheifinger H (2002) Changes in European spring phenology. Int J Climatol 22:1727-1738
Chmielewski FM, Rötzer T (2002) Annual and spatial variability of the beginning of growing season in Europe in relation to air temperature changes. Clim Res 19:257-264

> Crick HQP, Sparks TH (1999) Climate change related to egglaying trends. Nature 399:423-424

de Floriani L, Puppo E (1992) An on-line algorithm for constrained Delaunay triangulation. CVGIP: Graph Model Image Process 54:290-300

> Defila C, Clot B (2001) Phytophenological trends in Switzerland. Int J Biometeorol 45:203-207

> Dose V, Menzel A (2004) Bayesian analysis of climate change impacts in phenology. Glob Change Biol 10:259-272

Estrella N, Sparks TH, Menzel A (2007) Trends and temperature response in the phenology of crops in Germany. Glob Change Biol 13:1737-1747

> Hughes L (2000) Biological consequences of global warming: Is the signal already apparent? Trends Ecol Evol 15:56-61

> Menzel A (2000) Trends in phenological phases in Europe between 1951 and 1996. Int J Biometeorol 44:76-81

Menzel A (2003) Phenological anomalies in Germany and their relation to air temperature and NAO. Clim Change 57:243-263

Menzel A, Estrella N (2001) Plant phenological changes. In: Walther GR, Burga CA, Edwards PJ (eds) Fingerprints of climate change: adapted behaviour and shifting species ranges. Kluwer/Plenum, New York, p 123-137

> Menzel A, Fabian P (1999) Growing season extended in Europe. Nature 397:659

Menzel A, Estrella N, Fabian P (2001) Spatial and temporal variability of the phenological seasons in Germany from 1951 to 1996. Glob Change Biol 7:657-666

Menzel A, Sparks TH, Estrella N, Eckhardt S (2005) 'SSW to NNE'- North Atlantic Oscillation affects the progress of seasons across Europe. Glob Change Biol 11:909-918

Menzel A, Sparks T, Estrella N, Koch E and others (2006) European phenological response to climate change matches the warming pattern. Glob Change Biol 12:1969-1976

Menzel A, Estrella N, Heitland W, Susnik A, Schleip C, Dose V (2008) Bayesian analysis of the species-specific lengthening of the growing season in two European countries and the influence of an insect pest. Int J Biometeorol 52: 209-218

Parmesan C, Yohe G (2003) A globally coherent fingerprint of climate change impacts across natural systems. Nature 421:37-42

Root TL, Price JT, Hall KR, Schneider SH, Rosenzweig C, Pounds JA (2003) Fingerprints of global warming on wild animals and plants. Nature 421:57-60

Rosenzweig C, Casassa G, Karoly DJ, Imeson A and others (2007) Assessment of observed changes and responses in natural and managed systems. In: Parry ML, Canziani OF, Palutikof JP, van der Linden PJ, Hanson CE (eds) Climate change 2007: impacts, adaptation and vulnerability. Contribution of Working Group II to the Fourth Assessment Report of the Intergovernmental Panel on Climate Change. Cambridge University Press, Cambridge, p 79-131

> Rosenzweig C, Karoly D, Vicarelli M, Neofotis P and others (2008) Attributing physical and biological impacts to anthropogenic climate change. Nature 453:353-357

Schaber J (2002) Phenology in Germany in the 20th Century: methods, analyses and models. PhD thesis, University of Potsdam, available at http://pub.ub.uni-potsdam.de/2002/ 0022/schaber.pdf

> Scheifinger H, Menzel A, Koch E, Peter C, Ahas R (2002) Atmospheric mechanisms governing the spatial and temporal variability of phenological observations in central Europe. Int J Climatol 22:1739-1755 
Schleip C, Menzel A, Estrella N, Dose V (2006) The use of Bayesian analysis to detect recent changes in phenological events throughout the year. Agric For Meteorol 141:179-191

Schleip C, Menzel A, Dose V (2008) Norway spruce (Picea abies): Bayesian analysis of the relationship between temperature and bud burst. Agric For Meteorol 148:631-643

Schleip C, Rais A, Menzel A (2009) Bayesian analysis of temperature sensitivity of plant phenology in Germany. Agric For Meteorol 149:1699-1708

Schnelle F (1955) Pflanzen-Phänologie. Akademische Verlagsgesellschaft Geest \& Portig, Leipzig

Schwartz MD (1999) Advancing to full bloom: planning phenological research for the 21st Century. Int J Biometeorol 42:113-118

Schwartz MD, Ahas R, Aasa A (2006) Onset of spring starting earlier across the Northern Hemisphere. Glob Change Biol 12:343-351

Sparks TH (1999) Phenology and the changing pattern of bird

Submitted: March 5, 2009; Accepted: August 21, 2009 migration in Britain. Int J Biometeorol 42:134-138

Sparks TH, Carey PD (1995) The responses of species to climate over two centuries: an analysis of the Marsham phenological record. J Ecol 83:321-329

Sparks TH, Menzel A (2002) Observed changes in seasons: an overview. Int J Climatol 22:1715-1725

Sparks TH, Jeffree EP, Jeffree CE (2000) An examination of the relationship between flowering times and temperature at the national scale using long-term phenological records from the UK. Int J Biometeorol 44:82-87

Studer S, Appenzeller C, Defila C (2005) Interannual variability and decadal trends in Alpine spring phenology: a multivariate analysis approach. Clim Change 73:395-414

Walther GR, Post E, Convey P, Menzel A and others (2002) Ecological responses to recent climate change. Nature 416:389-395

Ziello C, Estrella N, Kostova M, Koch E, Menzel A (2009) Influence of altitude on phenology of selected plant species in the Alpine region (1971-2000). Clim Res 39:227-234

Proofs received from author(s): September 8, 2009 